\title{
La prensa digital ante la integración de los inmigrantes. Los casos del Zeit Online y The Times Online
}

\author{
Vicente LLORENT-BEDMAR \\ Universidad de Sevilla \\ llorent@us.es \\ Verónica Cobano-Delgado Palma \\ Universidad de Sevilla \\ cobano@us.es
}

Recibido: 8 de junio de 2014

Aceptado: 4 de diciembre de 2014

\begin{abstract}
Resumen
La prensa no es ajena al hecho migratorio. Con nuestra investigación pretendemos detectar qué actitudes fomenta. Con este objetivo hemos realizado un estudio comparado entre las ediciones digitales de dos diarios líderes en Alemania e Inglaterra: Zeit Online y The Times Online. A tal efecto, hemos utilizado la metodología propia de la Educación Comparada y el análisis de contenido de los artículos publicados entre enero de 2009 y junio de 2010.

Aunque existen diferencias significativas entre ellos, destacan sus similitudes. Entre ellas, su apoyo al proceso de integración de los inmigrantes a través de su adaptación a la sociedad receptora.

Palabras clave: Prensa digital, educación informal, inmigración, estereotipos, sociedad de la información.

\section{The role of the digital press to the integration of immigrants: Zeit Online y The Times Online}

\begin{abstract}
The press is not unaware to the migratory fact. With this study we try to detect the attitudes that the press foments. With this objective we carried out a comparative study of the digital versions of the two wide selling newspapers in Germany and England: Zeit Online and The Times Online. We used the same methodology as that used in Comparative Education, analysing the content of articles published between July 2012 and June 2013.

Although there are many differences between the two newspapers, there are many similarities. Between them, the support to the process of integration of the immigrants in the host society.

Keywords: Digital press, informal education, immigration, stereotypes, information society.

Referencia normalizada

LLORENT-BEDMAR, Vicente y COBANO-DELGADO PALMA, Verónica (2015): "La prensa digital ante la integración de los inmigrantes. Los casos del Zeit Online y The Times Online". Estudios sobre el Mensaje Periodístico. Vol. 21, Núm. 2 (julio-diciembre), págs.: 849-862. Madrid, Servicio de Publicaciones de la Universidad Complutense.

Sumario: 1. Introducción; 1.1. Educomunicación. 2. La prensa ante la multiculturalidad. 3. Fuentes y metodología; 3.1. Objetivos y unidades de comparación. 4. Desarrollo. 5. Conclusiones. 6. Referencias bibliográficas.
\end{abstract}




\section{Introducción}

La educación informal consiste en una acción difusa que se produce sin que su objetivo o intención sean meramente didácticos, aunque sí parte de sus consecuencias. Su magnitud y potencial son tales que deben ser estudiados y valorados adecuadamente. Transcendiendo la reduccionista visión de la educación constreñida a unos sistemas escolares tradicionales excesivamente centrados en la enseñanza meramente formal, estimamos que una parte importante de la educación que recibimos se encuentra fuera del recinto escolar. Sin lugar a dudas, la información transmitida a través de ámbitos tan diversos como la familia, la televisión, el cine, internet, la prensa... incide fuertemente en la formación de valores y actitudes.

Actualmente, en el terreno de las Ciencias de la Educación, están adquiriendo una notoria relevancia los aspectos educativos que se encuentran fuera del ámbito de los sistemas escolares. En este sentido, los medios de comunicación e información se constituyen en agentes de educación informal de enorme importancia que, paulatinamente, están adquiriendo mayor relevancia a causa del reciente crecimiento exponencial de las nuevas tecnologías. Así, entendemos la educación informal como "Todo conocimiento libre y espontáneamente adquirido, proveniente de personas, entidades, medios masivos de comunicación, medios impresos, tradiciones, costumbres, comportamientos sociales y otros no estructurados" (Observatorio Laboral para la Educación, 2014: web).

En efecto, los medios de comunicación han trascendido su inicial papel meramente informativo para constituirse en formadores de opinión y transmisores de valores. Situación ya atisbada por McLuhan, cuando nos advertía sobre la fuerza de este caudal informativo (Carpenter y McLuhan, 1974: 236), y nos avisaba de los peligros que acechaban a los que se quedaban fuera de la denominada aldea global (McLuhan, Fiore y Agel, 1971). McLuhan afirmaba que, debido al desarrollo de las comunicaciones se acortarían las distancias y se facilitaría el entendimiento entre las personas, produciéndose una transformación en toda la sociedad humana, que se asemejaría a una aldea global (McLuhan, 1969). Incluso en el terreno estrictamente escolar, hemos de indicar que la actual transformación social y los vertiginosos avances tecnológicos, han puesto en evidencia un sistema escolar aún basado en el formato papel que, anclado en la época industrial, requiere cambios de fondo para que la educación formal acabe por adaptarse a este ecosistema mediático (Parola y Delgado, 2013: 10).

\subsection{Educomunicación}

El cada vez más utilizado concepto de "sistema educativo" comprende, además del denominado "sistema escolar", una innumerable cantidad de contingencias educativas entre las que se encuentran los medios de comunicación. Su relevancia es tal, que se está conformando una prometedora rama del saber denominada Educomunicación, que "ha surgido como un nuevo espacio científico, que no es sino un cruce de caminos entre la educación y la comunicación... pero que cada vez más se vislumbra como un espacio diferente, desgajado de sus troncos comunes, y que tiene que ver con la transferencia de la información y del conocimiento" (García Galindo, 1999: 10). Ésta constituye un nuevo campo de estudio interdisciplinar y transdisciplinar que integra dos ramas del saber históricamente separadas: la educación y la comunicación. 
Desde la aparición de precursores de la educomunicación ${ }^{1}$ como Comenio (Comenio, 1988) o Freinet (Legrand, 1993), de las posteriores experiencias de Freire (Freire, 2005), de los análisis de Kaplún (Kaplún, 1998), y de las reflexiones de Umberto Eco acerca de las interacciones entre educación y comunicación (Eco, 1999), no ha dejado de acrecentarse el bagaje epistemológico de esta nueva especialidad (Parra, 2000).

Actualmente se considera la educomunicación como campo integrador caracterizado por su interdiscursividad, que ha de ser entendido desde una perspectiva interdisciplinar. En esta líneas, Ismar de Oliveira Soares afirma que es un "nuevo campo de intervención cultural social autónomo, denominado Interrelación Comunicación/Educación" (De Oliveira, 2000: 31).

No entendemos a la educomunicación desgajada de su finalidad cívica, sin su trasfondo ético y social relacionado con el empoderamiento de la ciudadanía en cuestiones mediáticas (Gozálvez y Contreras-Pulido: 2014: 130), y sin el objetivo de impulsar una ciudadanía más activa, crítica y participativa (Aguaded, 2013: 7). En este sentido afirmamos que la educación mediática, especialmente en su vertiente digital, debe desarrollar competencias claves que formen una ciudadanía más activa y comprometida (Mihailidis \& Thevenin, 2013). Durante las últimas décadas los medios electrónicos de comunicación se han convertido en poderosos agentes de socialización llegando a superar a la escuela y la familia. (Vera, 2006: 14).

\section{La prensa ante la multiculturalidad}

Las sociedades de Europa Occidental se caracterizan por su cada vez mayor multiculturalidad y creciente preocupación por otorgar a los colectivos de inmigrantes un adecuado tratamiento socioeducativo. Con el Tratado de Lisboa, que entró en vigor el 1 de diciembre de 2009, se reforzó el compromiso adquirido por la UE para el diseño de una política común de inmigración. En él se indica taxativamente que se ofrecerán medidas adecuadas en materia de inmigración y que «respetará la riqueza de su diversidad cultural y lingüística (...) (Diario Oficial de la Unión Europea, 2010: 17). No obstante, aun compartiendo una política común migratoria, cada país está llevando a cabo sus propias estrategias. Hecho que implica la existencia de un heterogéneo grupo de medidas de carácter nacional, estatal, autonómico, local, etc. Sin embargo, sí que cuentan con un extendido denominador común: la escasez de medidas destinadas a la población receptora, verdadero caldo de cultivo con el que han de convivir los ciudadanos foráneos. Siendo precisamente en este punto donde la acción formativa de la prensa adquiere gran relevancia.

Conjugar las culturas origen con la de llegada no siempre es fácil, sobre todo cuando se tratan aspectos esenciales. Si se desea evitar el indeseado asilamiento de colectivos y culturas foráneas, no solo se han de adoptar medidas encaminadas al colectivo inmigrante, sino que se han de plantear y promover estrategias dirigidas a la sociedad receptora. El papel de los medios de comunicación en la construcción del

1 Aunque se asigna la expresión educomunicación a Mario Kaplún, que la desarrolló a iniciativa de la UNESCO, en el entorno de Paulo Freire ya se utilizaba, circunstancia que no es de extrañar debido a las estrechas conexiones entre ambos y su pensamiento (MartínezSalanova, 2014: 1). 
pensamiento en torno al inmigrante y al hecho migratorio, constituye un elemento de indudable importancia en la creación y modelación de formas de pensar, actitudes y opiniones de la población receptora, ayudando o dificultando la integración de los colectivos foráneos. Junto con la formación académica inicial y la educación recibida en el entorno familiar, la más importante fuente de información/formación para la inmensa mayoría de los ciudadanos españoles está constituida por los medios de comunicación, entre los que la prensa adquiere una especial relevancia.

La información que cada individuo recibe juega un papel fundamental en la conformación de su personalidad, en el concepto de sociedad que tiene y en su relación con los demás. La formación que a lo largo de nuestras vidas vamos adquiriendo incide directamente en la forma de concebir al otro, al "distinto". Los medios de comunicación tienen un esencial papel que desempeñar en la formación de los ciudadanos, máxime en estos momentos en los que su influjo ha adquirido una más que notable dimensión. Esta creciente influencia se ha visto beneficiada por la gratuidad y el fácil acceso a la mayoría de la prensa digital.

Con los albores del s. XXI, en plena crisis del sector, se produjo un fuerte crecimiento de los diarios digitales, a la vez que se redefinían sus estrategias empresariales tendiendo a buscar una eficaz rentabilidad de las ediciones digitales. Siendo numerosas las alteraciones que ha provocado el surgimiento del periodismo digital (Rubio, 2005: 153), entre ellas cabe destacar dos aspectos de especial relevancia: A. Permiten que el flujo informativo sea continuo y, por ende, la permanente actualización de los textos (Caminos et al, 2007: 334). B. Los medios digitales han multiplicado los espacios de participación del público (Pastor, 2012: 193).

\section{Fuentes y metodología}

En primer lugar, se escogió el tema objeto de estudio, los artículos sobre inmigración, y se delimitaron las unidades de comparación, circunscritas a las ediciones digitales de los diarios The Times Online y Zeit Online. Posteriormente, se analizaron los artículos aparecidos sobre el tema en las mencionadas ediciones, desde el 1 de julio de 2012 hasta el 30 de junio de 2013, ambos días comprendidos, lo que supuso un periodo total de un año. De modo que se seleccionaron todos los artículos aparecidos en este espacio temporal que incluyeran los vocablos "immigration" y "education" para la revista británica, y los de "migration" y "bildung" para la revista alemana. El número de artículos que reunió estas condiciones se elevó a 70 en el caso de The Times Online y 52 en el caso del Ziet Online.

A través del análisis de contenido se examinaron de forma objetiva y sistemática los artículos objeto de estudio. Se realizó una selección de las categorías utilizadas, de las unidades de análisis y del sistema de recuento de la información obtenida. Esta técnica posee características cualitativas compatibles con las cuantitativas, aunque inicialmente Berelson, fundador del análisis de contenido, afirmara que ésta es "una técnica de investigación para la descripción objetiva, sistemática y cuantitativa del contenido manifiesto de la comunicación" (Berelson, 1952: 18). Pues bien, ésta nos permitió codificar distintas partes del mensaje emitido, facilitándonos su transformación en datos analizables, a través de la elaboración de categorías excluyentes. 
Una vez efectuado el pertinente análisis de contenido se llevó a cabo un estudio comparado empleando la metodología propia de la Educación Comparada. Con tal objeto se ha partido de los planteamientos conceptuales de los profesores García Garrido y Llorent Bedmar, quienes conciben la Educación Comparada como ciencia de la educación que se caracteriza por estudiar los sistemas educativos utilizando la metodología comparada. Dadas las características de esta investigación, de claro sesgo social, se ha de remarcar el carácter interdisciplinar de la misma. En consonancia con las línea metodológica expuestas por García Garrido (García, 1991: 150-162), se han seguido las fases para la realización de una investigación comparada propuestas por Llorent Bedmar (Llorent, 2002).

\subsection{Objetivos y unidades de comparación}

La finalidad del presente estudio consiste en poner de relieve la importancia de la prensa digital en la formación de opinión que tienen los ciudadanos, detectando si fomenta actitudes positivas o negativas en torno al hecho migratorio. Para alcanzarla nos planteamos dos objetivos primordiales: Estudiar el tratamiento que recibe el hecho migratorio en los artículos de dos importantes diarios online de Inglaterra y Alemania, y constatar diferencias y similitudes que, en torno a él, muestran ambos diarios. Coadyuvando de este modo a una mayor toma de conciencia sobre la incidencia educativa y formativa de la prensa. Con esta pretensión se ha realizado un estudio comparado centrado en el análisis de contenido de las ediciones digitales de dos relevantes diarios digitales, que conforman nuestras dos unidades de comparación: el británico The Times Online (http://www.thetimes.co.uk/tto/news/) y el alemán Zeit Online (http://www.zeit.de/index).

El primero es un prestigioso diario de distribución nacional, decano de la prensa inglesa. Su talante conservador, de ideología centro-derecha, ha propiciado que, frecuentemente, sea tildado de portavoz del "establishment" británico (Press Europ, 2011: web). Su antigüedad e influencia le coloca en un lugar privilegiado dentro de la prensa del Reino Unido. Fue fundado por John Walter el 1 de enero de 1785, bajo el nombre de The Daily Universal Register, adquiriendo su actual denominación en 1788. Actualmente, y concretamente desde 1981, la sociedad comercial News Corporation de Rupert Murdoch pasó a hacerse cargo del mismo mediante la compra de Times Newspapers (Encyclopaedia Britannica, 2014: web).

Este diario cuenta con una versión online desde el mes de marzo de 1999. En su origen la dirección web para acceder al mismo era www.the-times.co.uk y, posteriormente pasó a www.timesonline.co.uk. Dirección que sigue empleándose a día de hoy (E-Paper Catalog, 2014: web). Además existen ediciones de The Times Online para iPad y Android. Desde el mes de julio del año 2010, el propietario de News International estableció una cuota de $£ 1$ para los lectores que quisieran suscribirse a la modalidad online diaria de The Times, y de $£ 2$ para la suscripción semanal digital de The Times, a pesar del posible riesgo que esta medida conllevaba (BBC, 2010: web).

Tres años después de la estrategia de suscripción, The Times online, junto con The Sunday Times han reunido un total de 140.000 suscriptores digitales de pago, la mayoría de ellos, a través de las tablets. Además, se ha producido un aumento del número 
de suscriptores digitales totales desde el año 2010 hasta el 2013 (Smith, 2013: web). Actualmente, The Times Online cuenta con un total de 375.882 suscriptores (The Times, 2014: web).

Este diario digital tiene un estilo sobrio, cuenta con una interfaz ordenada y limpia, con "pocos banners" y sin los intrusivos "pop-ups". Los artículos mantienen su extensión y se facilita su lectura con diferentes pestañas desplazables al estilo de The New York Times. La reputación seria de este diario, respalda con secciones como política, economía y cultura, se complementa con un logrado lenguaje visual a través de imágenes, y con la inmediata disponibilidad de cualquier noticia relevante. Este diario digital distingue con claridad aquello que corresponde a la edición online con lo que pertenece a la edición impresa (Armentia, 2002: 1). No fue hasta el 2 de julio de 2010 cuando el diario comenzó a cobrar a sus lectores online el acceso a sus contenidos (Brignardello, 2010: web).

Nuestra segunda unidad de comparación, el Ziet Online, tiene sus orígenes en el periódico Die Zeit (Zeitverlag Gerd Bucerius GmbH \& Co. KG.), semanario alemán de tendencia socio-liberal, de distribución nacional y de mayor tirada semanal en Alemania (La Información, 2012: web). Con sede en la ciudad de Hamburgo (Hernández, 2000), realizó su primera publicación el 21 de febrero de 1946. En 2011 sus ventas alcanzaron cifras record, situándose muy por encima de sus competidores (About International media, 2011: web). En mayo de 2013 fue elegido como el mejor semanal europeo del año por la asociación alemana Editorial Design (El Espectador, 2013: web).

Este diario posee una versión online -Zeit Online- en cuya redacción trabajan alrededor de 60 personas. En esta edición digital se publican algunos artículos incluidos en la edición impresa (Lucchini, 2010: web). El acceso a tales artículos, así como a aquellos contenidos en formato digital, es completamente gratuito. Existen, adicionalmente, modalidades de suscripción al periódico que permiten a quienes se suscriban acceder a los contenidos en formato MP3 (Die Zeit, 2014: web). En enero de 2014, el número total de ventas era de 22.755, elevándose las suscripciones a 10.145, de las cuales más del 90\% eran realizadas utilzando iTunes, Amazon o directamente desde Zeit Online (Informationsgemeinschaft zur Feststellung der Verbreitung von Webeträgern e. V.: 2014).

Zeit Online constituye una de las mayores y más sofisticadas plataformas de habla alemana en el ámbito del periodismo en línea. Este diario digital destaca por su excelente clasificación analítica de los acontecimientos a nivel mundial, por su atractivo diseño visual, así como en los exigentes debates entre sus lectores (Leserdebatten). Aún más, el diálogo entre lectores y redactores no tiene lugar únicamente a través de www.zeit.de, sino que adicionalmente se presenta mediante redes sociales como Facebook, Twitter, YouTube y Google+ (Zeit-Verlagsgruppe, 2014: 1).

\section{Desarrollo}

Para realizar el análisis de los resultados y lograr una mejor comprensión del estudio comparado realizado, se han establecido una serie de categorías, de las que seleccionamos las más relevantes. Así, inicialmente nos detendremos en uno de los aspectos 
que captan la atención del lector desde el primer momento, nos referimos a las imágenes. El uso de representaciones pictóricas que ilustran el contenido de los artículos constituye un potente instrumento de transmisión de información y, por tanto, un medio de educativo de gran interés. Éstas ilustran el 61,4\% de los artículos analizados de The Times Online y el 25\% de Ziet Online. En este último diario, son las imágenes de inmigrantes $(53,8 \%)$ las que aparecen con mayor frecuencia, mientras que en The Times Online se muestran más bien imágenes simbólicas y alegóricas.

Tabla 1: En caso afirmativo ¿quiénes se ven?

\begin{tabular}{|l|r||r||r||r||}
\cline { 2 - 4 } \multicolumn{1}{c|}{} & \multicolumn{2}{c|}{ The Times Online } & \multicolumn{2}{c|}{ Ziet Online } \\
\cline { 2 - 5 } \multicolumn{1}{c|}{} & \multicolumn{1}{c|}{ f } & $\mathbf{\%}$ & f & $\%$ \\
\hline \hline Personajes políticos & 10 & 23,3 & 2 & 15,4 \\
\hline \hline Inmigrantes & 11 & 25,6 & 7 & 53,8 \\
\hline \hline Otros & 22 & 51,2 & 4 & 30,8 \\
\hline \hline Total & $\mathbf{4 3}$ & $\mathbf{1 0 0 , 0}$ & $\mathbf{1 3}$ & $\mathbf{1 0 0 , 0}$ \\
\hline \hline
\end{tabular}

Profundizando en la visión que a través de las ilustraciones se ofrece de la inmigración, hallamos que mayoritariamente y en ambos casos $(60,5 \%$ The Times Online y $61,5 \%$ Ziet Online) se trata de una imagen neutra, sin connotaciones positivas ni negativas. En el caso de The Times Online hemos encontrado un 23,3\% de imágenes que transmiten una visión positiva frente a un $16.3 \%$ negativa. Mientras que en el Ziet Online la diferencia es más que considerable, un $30,8 \%$ en el primer caso por un $7,7 \%$ en el segundo.

Si analizamos los titulares del artículo, que sin duda constituyen uno de los aspectos que llaman más la atención al lector, observamos como en The Times Online un elevado porcentaje de ellos $(84,3 \%)$ no emplean los términos "inmigrante", ni "extranjero", ni si quiera la nacionalidad del colectivo. En esta faceta sí que constatamos diferencias altamente significativas con el Ziet Online. En efecto, en este segundo diario observamos la ausencia de estos términos tan solo en un $42,3 \%$ de los casos, entre ellos un nada desdeñable $26,9 \%$ se refieren a la nacionalidad del grupo y un $25 \%$ incluyen el vocablo "inmigrante". En el caso de las nacionalidades hemos observado que en The Times Online los artículos se centran con una mayor frecuencia en colectivos procedentes de la India, mientras que en el Ziet Online preponderan los artículos sobre el colectivo de origen turco.

Tabla 2: Término utilizado en el titular

\begin{tabular}{|l||r||r|r|r||}
\cline { 2 - 5 } \multicolumn{1}{c|}{} & \multicolumn{2}{c|}{ The Times Online } & \multicolumn{2}{c|}{ Ziet Online } \\
\cline { 2 - 5 } \multicolumn{1}{c||}{} & f & \% & f & \% \\
\hline Inmigrante & 3 & 4,3 & 13 & 25,0 \\
\hline Extranjero & 6 & 8,6 & 3 & 5,8 \\
\hline Nacionalidad & 2 & 2,9 & 14 & 26,9 \\
\hline Nada & 59 & 84,3 & 22 & 42,3 \\
\hline Total & $\mathbf{7 0}$ & $\mathbf{1 0 0 , 0}$ & $\mathbf{5 2}$ & $\mathbf{1 0 0 , 0}$ \\
\hline \hline
\end{tabular}


En esta misma sintonía observamos como en la mayor parte de los textos analizados de ambos diarios se nombra o interviene algún partido o personalidad política de forma prolífica. Es decir, en el 68,6\% y en el 53,8\% de los casos del The Times Online y del Ziet Online, respectivamente.

Tabla 3: ¿Se nombra o interviene en el artículo algún partido/personaje político?

\begin{tabular}{|c|c|c|c|c|}
\hline & \multicolumn{2}{|c|}{ The Times Online } & \multicolumn{2}{|c|}{ Ziet Online } \\
\hline & f & $\%$ & f & $\%$ \\
\hline Sí & 48 & 68,6 & 28 & 53,8 \\
\hline No & 22 & 31,4 & 24 & 46,2 \\
\hline Total & 70 & 100,0 & 52 & 100,0 \\
\hline
\end{tabular}

Al analizar la visión que del fenómeno migratorio se transmite a través de ambos portales de prensa digital, comprobamos como mayoritariamente, en los artículos publicados existe algún colectivo, bien pertenezca a la sociedad de origen bien a la receptora, afectado directamente por el tema que se narra $(71,4 \%$ en The Times Online y $94,2 \%$ en Ziet Online). Profundizando en esta variable, constatamos como en el $37,1 \%$ de los artículos analizados en el diario británico se muestra como grupo afectado al colectivo inmigrante, mientras que un $20 \%$ recaen sobre la sociedad autóctona y un $14,3 \%$ de los casos se refiere a ambos grupos. Mientras que en el diario alemán observamos una tendencia distinta, el mayor porcentaje hallado $(46,2 \%)$ muestra a ambos grupos como los afectados en la noticia que se transmite, el $42,3 \%$ se refiere al colectivo inmigrante, y resta un reducido $5,8 \%$ de artículos referidos al colectivo autóctono.

Al estudiar la existencia de términos o adjetivos que vinculen al colectivo inmigrante con valores negativos, se constató como esta circunstancia concurría en una minoría de casos, tanto en The Times Online (15,7\%) como en Ziet Online (7,7\%). Para estos reducidos casos, observamos que los términos utilizados con mayor frecuencia en el primer diario era el de "ilegales" y, en el segundo "sin papeles".

Tabla 4: ¿Hay algún grupo afectado?

\begin{tabular}{|l||r|r||r||r||}
\cline { 2 - 5 } \multicolumn{1}{c|}{} & \multicolumn{2}{c|}{ The Times Online } & \multicolumn{2}{c|}{ Ziet Online } \\
\cline { 2 - 5 } \multicolumn{1}{c|}{} & f & $\mathbf{\%}$ & f & $\mathbf{\%}$ \\
\hline Sí, el colectivo autóctono & 14 & 20,0 & 3 & 5,8 \\
\hline \hline Sí, el colectivo inmigrante & 26 & 37,1 & 22 & 42,3 \\
\hline No & 20 & 28,6 & 3 & 5,8 \\
\hline \hline Sí, ambos & 10 & 14,3 & 24 & 46,2 \\
\hline Total & $\mathbf{7 0}$ & $\mathbf{1 0 0 , 0}$ & $\mathbf{5 2}$ & $\mathbf{1 0 0 , 0}$ \\
\hline
\end{tabular}

En la sociedad del bienestar instaurada en los países de Europa Occidental, donde la economía del país se conforma como una de las primeras preocupaciones de los ciudadanos, sorprende observar como los diarios estudiados apenas relacionan el hecho migratorio con la actual crisis económica, tan solo se produce en el $27,1 \%$ y en el $17,3 \%$ de los casos, respectivamente. 
Por otro lado, hallamos como la mayoría de los artículos analizados hacen mayor hincapié en el bienestar de la población autóctona por encima del colectivo inmigrante. Diferencia más pronunciada en el caso de The Times Online (77,8\%), frente a 53,8\% del Ziet Online.

Tabla 5: Se hace más hincapié en el bienestar de

\begin{tabular}{|l|r|r||r|r||}
\cline { 2 - 5 } \multicolumn{1}{c|}{} & \multicolumn{2}{c|}{ The Times Online } & \multicolumn{2}{c|}{ Ziet Online } \\
\cline { 2 - 5 } \multicolumn{1}{c|}{} & f & $\mathbf{\%}$ & \multicolumn{1}{c|}{ f } & $\%$ \\
\hline \hline Población autóctona & 49 & 77,8 & 28 & 53,8 \\
\hline \hline Población inmigrante & 14 & 22,2 & 20 & 38,5 \\
\hline \hline Ambos & 0 & 0 & 4 & 7,7 \\
\hline \hline Total & $\mathbf{6 3}$ & $\mathbf{1 0 0 , 0}$ & $\mathbf{5 2}$ & $\mathbf{1 0 0 , 0}$ \\
\hline \hline
\end{tabular}

Aunque es evidente la relación existente entre religión e inmigración, constituyendo fuente de controversias, comprobamos como, paradójicamente, apenas es tratada por The Times Online (90\%) y por el Ziet Online $(76,9 \%)$. En efecto, la mayoría de los artículos analizados no se centran en este ámbito y cuando se refieren a él no lo hacen de forma negativa (tan sólo en 2 ocasiones en cada uno de los diarios). Lo mismo ocurre con el tema de los signos religiosos, en un $92,9 \%$ y $82,7 \%$ de los casos en los respectivos diarios no se trata el tema y cuando se hace, son ínfimos los casos que ofrecen una visión negativa de la cuestión ( 2 y 3 casos respectivamente).

En cuanto al proceso de integración del colectivo inmigrante en la sociedad receptora, los datos obtenidos reflejan que en el 78,6\% de los artículos analizados en The Times Online no se promueve un proceso de integración del colectivo inmigrante en la sociedad de llegada, mientras que en Ziet Online lo observamos en el 92,3\% de los casos. No obstante, al indagar sobre el procedimiento a través del cual se ha de efectuar dicha integración se constata que, en aquellos artículos en los que se comenta el tema en cuestión ( 15 en el caso de The Times Online y 18 en Ziet Online), el 80\% de los publicados en The Times Online expresan que para alcanzar la deseada convivencia entre inmigrantes y autóctonos, los primeros deben adaptarse a las normas y pautas establecidas en la sociedad receptora. Estrategia similar se plantea en el 72,2\% de los artículos analizados en Ziet Online.

Respecto a si los artículos apoyan que los inmigrantes participen en la vida social del país de llegada, comprobamos como, en ambos periódicos, mayoritariamente no tratan el tema (62,9\% The Times Online y 53,8\% Ziet Online). En cambio, si analizamos sólo los que sí tratan la cuestión observamos diferencias entre los diarios estudiados. En el caso de The Times Online encontramos un porcentaje más elevado de artículos que no apoyan dicha cuestión (20\%), mientras que en el de Ziet Online preponderan las afirmativas $(34,6 \%)$.

Refiriéndonos a la visión que se ofrece sobre la convivencia entre el colectivo inmigrante y la sociedad receptora, hallamos nuevamente diferencias entre ambos diarios, aunque cuentan con un denominador común, su mayoritaria tendencia a dar una visión neutra del asunto (61,4\% en The Times Online y 44,2\% en Ziet Online). Así, en la versión digital de The Times a este porcentaje mayoritario le sigue el 25,7\% de artículos que desprenden una visión negativa; mientras que en Ziet Online el segundo 
lugar le corresponde a los que ofrecen una visión positiva (40,4\%). En esta línea argumental, destacamos que aunque en un altísimo porcentaje no relacionan la inmigración con la delincuencia $(87,1 \%$ y $92,3 \%$, respectivamente), hallamos una proporción baja, pero no por ello baladí, en los que sí se lleva a cabo esta analogía, el $12,9 \%$ en The Times Online y el 7,7\% en Ziet Online.

Por último, si analizamos la causa o motivo principal que se transmite en el artículo hallamos de nuevo diferencias entre ambas publicaciones. Al estudiar su repercusión en la sociedad receptora, observamos que en una buena parte de los artículos de The Times Online se muestra como negativa (55,7\%), mientras que en Ziet Online es positiva $(42,3 \%)$. Pero si nos referimos a las consecuencias en la sociedad de origen, advertimos que la mayoría de artículos de The Times Online tienen una tendencia también negativa $(61,4 \%)$, mientras que en el Ziet Online es nuevamente positiva $(46,2 \%)$.

\section{Conclusiones}

Tras la investigación realizada, constatamos la existencia de claras similitudes entre los dos diarios digitales objeto de nuestro estudio, al igual que unas apreciables diferencias. Respecto a las primeras destacamos cómo las ilustraciones que aparecen en los artículos se utilizan de una forma generalizadamente neutra. Aunque en segundo lugar destaca la visión positiva que éstas transmiten en el Zeit Online.

Por el contrario hallamos diferencias significativas en los vocablos utilizados en los titulares de los diarios analizados. En The Times Online apenas se utilizan términos que denoten la pertenencia del individuo al colectivo de inmigrantes, extranjeros o de origen distinto al británico. Mientras que en el Ziet Online este porcentaje no llega ni siquiera al $50 \%$.

Adentrándonos en el contenido de los artículos constatamos que en el diario británico, mayoritariamente, se muestra como grupo afectado al colectivo inmigrante. Mientras que en el diario alemán esta situación recae sobre ambos colectivos, siguiéndoles a corta distancia el colectivo de inmigrantes. Resultados que ponen de manifiesto distintas maneras de orientar el mensaje transmitido a través de los artículos publicados.

Si nos centramos en la causa o motivo principal sobre el que giran los artículos, constatamos como en The Times Online tiene un mayoritario carácter negativo, bien para la sociedad de receptora bien para la de origen. Mientras que en Ziet Online es positiva para ambos colectivos.

También observamos una serie de características que concuerdan con una visión políticamente correcta del hecho migratorio. En estos diarios apenas aparecen vocablos que indiquen negatividad o que tengan carácter peyorativo para con los inmigrantes, mostrando una escasa relación entre inmigración con la delincuencia. Además, sorprende como en la sociedad del bienestar alemana e inglesa, donde la economía del país se conforma como una de las primeras preocupaciones de los ciudadanos, los diarios analizados apenas relacionan el hecho migratorio con la actual crisis económica. Ni siquiera la evidente y, a veces, controvertida relación entre religión e inmigración apenas se ve reflejada. En esta misma línea, también constatamos como en los 
dos diarios se nombran o intervienen en unos elevados porcentajes algún partido o personalidad política. Todos estos datos nos inducen a pensar que se produce cierta politización del hecho migratorio, en este caso, en su faceta positiva. Lo cual no es óbice para que, por otro lado, también detectemos como hacen más hincapié en el bienestar de la población autóctona, por delante del colectivo inmigrante, especialmente en el diario británico $(77,8 \%)$.

Finalizamos destacando como los dos diarios transmiten mayoritariamente una visión neutra sobre la convivencia de ambos colectivos. A la vez, promueven una adecuada integración del colectivo inmigrante, coincidiendo en el modo en el que ésta se debería llevar a cabo: a través de la adaptación del inmigrante a las normas y pautas establecidas en la sociedad receptora.

Esta discutible estrategia, muy alejada de las posiciones francesa y española, no se entendería correctamente sin tener en cuenta las políticas sobre inmigración tradicionalmente adoptadas en Inglaterra y Alemania. En Inglaterra se pretende que el inmigrante se integre en su propia minoría étnica y ésta ocupe el lugar que le corresponde junto con la mayoría y las demás minorías. En Alemania no se les considerará alemanes de "sangre", implícitamente se supone que cuando se extingan sus contratos volverán a sus países de origen. Desde esta perspectiva, se comprende como el modelo propugnado por los diarios analizados, además de coincidir con las líneas editoriales de los mismos, se encuentre en las antípodas de considerar la integración como un proceso de adaptación mutua.

Finalizamos, afirmando que siendo cierto que la construcción de la sociedad es responsabilidad de todos, no lo es menos que no todos contamos con la gran influencia que poseen los medios de comunicación. En este sentido, estimamos que los diarios estudiados están ejerciendo su labor en consonancia con el grado de responsabilidad que les corresponde.

\section{Referencias bibliográficas}

ABOUT INTERNATIONAL MEDIA (2011): "Record de difusión del periódico alemán Die Zeit": http://www.aboutim.es/record-de-difusion-del-periodico-alemandie-zeit/ [Consulta: 2 de mayo de 2014].

AGUADED, José Ignacio (2013): "El programa «Media» de la Comisión Europea, apoyo internacional a la educación en medios". Comunicar, 40, pp. 7-8. http://dx.doi.org/10.3916/C40-2013-01-01

ARMENTIA, José Ignacio (2002): "Tendencias en el periodismo digital. Curso de Doctorado": http://www.ehu.es/jiarmentia/doctorado/doctorado2002/tema08.htm [fecha de consulta: 12 de mayo de 2014].

BBC NEWS (2010): "Times and Sunday Times websites to charge from June": http://news.bbc.co.uk/1/hi/business/8588432.stm [fecha de consulta: 14 de abril de 2014].

BERELSON, Bernard (1952): Content Analysis in Communication Research. New York, Free Press. 
BRIGNARDELLO, Antonella (2010): "The Times comienza a cobrar por su versión digital", en ABC: http://www.abc.com.py/ciencia/the-times-comienza-a-cobrarpor-su-edicion-digital-125997.html [Consulta: 14 de mayo de 2014].

CAMINOS, José María et al. (2007): "Elementos definitorios del Periodismo Digital". Estudios sobre el Mensaje Periodístico, $\mathrm{n}^{\circ}$ 13, pp. 317-336. Madrid, Servicio de Publicaciones de la Universidad Complutense.

CARPENTER, Edmun y MCLUHAN, Marshall (1974): El aula sin muros. Barcelona, Laia.

COMENIO, Juan Amós (1988): Didáctica Magna. México, Editorial Porrúa.

DE OLIVEIRA SOARES, Ismar (2000): “Comunicação - Educação: A emergência de um novo campo e o perfil de seus profissionais": http://www.ricardojapiassu.pro.br /ISMAR.htm [fecha de consulta: 16 de mayo de 2014].

DIARIO OFICIAL DE LA UNIÓN EUROPEA (2010): Versión consolidada del Tratado de la Unión Europea. Comunicaciones e Informaciones, marzo, C 83.

ECO, Umberto (1999): La estrategia de la ilusión. Barcelona, Lumen.

EL ESPECTADOR (2013): Periódico alemán Die Zeit, mejor periódico semanal europeo del año: http://www.elespectador.com/noticias/elmundo/articulo-420385-periodico-aleman-die-zeit-mejor-semanal-europeo-del-ano [fecha de consulta: 21 de abril de 2014].

ENCYCLOPAEDIA BRITANNICA (2014): “The Times": http://www.britannica.com /EBchecked/topic/596228/The-Times [Consulta: 12 de abril de 2014].

E-PAPER CATALOG (2014): “The Times E-Paper": http://www.epapercatalog .com/epaper/the-times-epaper.php [fecha de consulta: 12 de abril de 2014].

FREIRE, Paulo (2005): Pedagogía del oprimido. México, Siglo XXI.

GARCÍA GALINDO, Juan Antonio (1999): “Comunicación, Educación y Democracia". Comunicar, 13, pp. 10-12.

GARCÍA GARRIDO, José Luis (1991): Fundamentos de Educación Comparada. Madrid, Dykinson.

GOZÁLVEZ, Vicente y CONTRERAS-PULIDO, Paloma (2014): "Empoderar a la ciudadanía mediática desde la educomunicación”. Comunicar, n 42, pp. 129-136. http://dx.doi.org/10.3916/C42-2014-12

HERNÁNDEZ, Rita (2000): "Las Islas Canarias desde la Prensa alemana: Fuentes, metodología y enfoque de un estudio socio-histórico sobre el turismo del siglo XX", en MORALES, Francisco (Coord.): VIII Congreso Internacional de Historia de América. Las Palmas de Gran Canaria, Casa de Colón/Cabildo de Gran Canaria.

INFORMATIONSGEMEINSCHAFT ZUR FESTSTELLUNG DER VERBREITUNG VON WEBETRÄGERN E. V.: Die Zeit davon ePaper: $\mathrm{http}: / /$ daten.ivw.eu/index.php?menuid=1\&u=\&p=\&detail=true [Consulta: $15 \mathrm{de}$ mayo de 2014]. 
KAPLÚN, Mario (1998): Una pedagogía de la comunicación. Madrid, Ediciones de la Torre.

LA INFORMACIÓN (2012): "Publicado programa para asegurar el envío de contenido anónimo a medios en línea": http://noticias.lainformacion.com/economia-negocios-y-finanzas/periodicos-y-revistas/publicado-programa-para-asegurar-el-envi o-de-contenido-anonimo-a-medios-en-linea_yWKuJFYQtD2QwVLmVOnlV2/ [Consulta: 1 de junio de 2014].

LEGRAND, Louis (1993): Célestine Freinet: Una vida excepcional. Paris, Unesco.

LLORENT-BEDMAR, Vicente (2002). Educación Comparada. Sevilla, Universidad de Sevilla.

LUCCHINI, Laura (2010): "Reportaje: Giovanni di Lorenzo, director del semanario alemán 'die Zeit'. El futuro de la prensa. El periodismo digital hace de todo menos dinero, en El Pais: http://elpais.com/diario/2010/10/31/domingo/1288497158 850215.html [Consulta: 2 de abril de 2014].

MARTÍNEZ-SALANOVA, Enrique (2014): "Educomunicación. Aprendizaje y creatividad en la educación para los medios". Revista Aularia. El país de las aula, n ${ }^{\circ}$ 3 , pp. 1-2.

MCLUHAN, Marshall (1969): La galaxia Gutenberg: génesis del "homo typographicus". Madrid, Aguilar.

MCLUHAN, Marshall; FIORE, Quentin; y AGEL, Jerome (1971): Guerra y Paz en la Aldea Global. Barcelona, Ediciones Martínez Roca.

MIHAILIDIS, Paul y THEVENIN, Benjamin (2013). "Media Literacy as a Core Competency for Engaged Citizenship in Participatory Democracy". American Behavioral Scientist, $\mathrm{n}^{\circ}$ 57, pp. 1-12. http://dx.doi.org/10.1177/0002764213489015

OBSERVATORIO LABORAL PARA LA EDUCACIÓN (2014): "Glosario", en: http://www.graduadoscolombia.edu.co/html/1732/propertyvalue-37638.html [fecha de consulta: 1 de abril de 2014].

PAROLA, Alberto y DELGADO, Águeda (2013): "La urgencia de la competencia mediática en los programas escolares". Chasqui, no 124, pp. 4-10.

PARRA, Germán (2000): Bases epistemológicas de la educomunicación. Quito, Ediciones ABYA-YALA.

PASTOR, Lluís (2012): "Las nuevas reglas de la participación del público en la prensa digital. Análisis de siete diarios europeos de referencia". Estudios sobre el Mensaje Periodístico, $\mathrm{n}^{\mathrm{o}}$ 18, pp. 193-210. http://dx.doi.org/10.5209/rev_ESMP.2012 .v18.n1.39365. Madrid, Servicio de Publicaciones de la Universidad Complutense.

PRESS EUROP (2011): “The Times": http://www.presseurop.eu/es/content/sourceinformation/30091-times [Consulta: 10 de abril de 2014].

RUBIO, María (2005): "Nuevos tiempos para la documentación informativa en el periodismo digital: viejas y nuevas funciones del servicio de documentación digital". Comunicación y Sociedad, nº 18, pp. 153-168. 
SMITH, Patrick (2013): "Three years on: Has the times digital subscription project worked?", en The Media Briefing: http://www.themediabriefing.com/article/timesdigital-subscribers-reach-140-000-as-paywall-project-reaches-maturity [Consulta: 15 de abril de 2014].

THE TIMES (2014): “The Times". http://www.thetimes.co.uk/tto/news/ [Consulta: 15 de mayo de 2014].

VERA, Eland (2006): "Los weblogs como herramienta educomunicativa", en: http://autocosmofilia2.blogspot.com/2006_02_01_archive.html [Consulta: 25 de abril de 2014].

ZEIT-VERLAGSGRUPPE (2014): "Zeit Online": http://www.zeit-verlagsgruppe.de /marken-und-produkte/\#akkordeon_2_2 [Consulta: 25 de abril de 2014].

ZEIT ONLINE (2014): http://www.zeit.de/index [Consulta: 2 de abril de 2014] 